\title{
Sequential Load Transport in Grass-Cutting Ants (Atta vollenweideri): Maximization of Plant Delivery Rate or Improved Information Transfer?
}

\author{
Jacqueline Röschard and Flavio Roces \\ Department of Behavioral Physiology and Sociobiology (Zoology II), Biocenter, University of Würzburg, Am Hubland, \\ 97074 Würzburg, Germany \\ Correspondence should be addressed to Flavio Roces, roces@biozentrum.uni-wuerzburg.de
}

Received 7 March 2011; Accepted 14 April 2011

Academic Editor: Felipe Andrés León Contrera

Copyright ( $\odot 2011$ J. Röschard and F. Roces. This is an open access article distributed under the Creative Commons Attribution License, which permits unrestricted use, distribution, and reproduction in any medium, provided the original work is properly cited.

Sequential transport of plant fragments was studied in the grass-cutting ant Atta vollenweideri. Two competing hypotheses concerning its occurrence were tested. Based on the "economic-transport hypothesis," sequential transport occurs because of a mismatch between load size and ant body size, and it is therefore considered a way to improve size-matching and so the plant delivery rate. Alternatively, the "information-transfer hypothesis" states that sequential transport improves the information flow during foraging. By transferring its load, a worker may return earlier to the foraging site so as to intensify chemical recruitment. To distinguish between these two competing hypotheses, standardized paper fragments that differed either in size or in quality were presented to workers of a field colony, and sequential transport was quantified. Neither an increase in fragment mass nor in fragment length influenced the occurrence of transport chains. Sequential transport took longer than transport by a single carrier. However, the occurrence of sequential transport increased with increasing fragment quality. High-quality fragments were transferred more frequently and after shorter distances than less-attractive fragments. Taken together, these results strongly support the hypothesis that sequential load transport has been favoured during evolution because of an improvement in the information flow during foraging.

\section{Introduction}

Ant colonies are highly organized societies without central control, yet with mechanisms that permit workers to respond to colony needs, and consequently engage in different task required for colony function such as foraging, nest construction, and brood tending. In addition to simultaneously coordinated activities such as cooperative food transport and resource defense [1-3], ants also show serially organized work, in which a given task is partitioned into two or more sequential stages, for instance, when a food item or building material is passed consecutively from one worker to the next. Several investigations have highlighted details on sequential processing of material not only in ants [4-8], but also in wasps [9], bees [10,11], and humans [12]. For social insects, in general, sequential transport was described mostly in the context of foraging, but also during nest building [13] and waste transport [14].

Compared to a nonsequential mode, sequential material processing has several advantages, for instance, a decrease in both the time and energy required to perform the activity $[12,15,16]$, which may result from a more efficient individual performance, or an improved co-ordination between individuals [9]. A sequential transport of collected material implies that the task is partitioned among different workers, and linked by material transfer. Task partitioning is defined as a process in which one task is split up between different worker groups, in contrast to division of labor in which different tasks are performed by different worker groups $[9,13,16,17]$.

Leaf-cutting ants of the tribe Attini show both division of labor $[18,19]$ and task partitioning to an extraordinary 
extent [20], including different contexts such as foraging [4, 21], trail construction [22], or waste disposal [23]. Sequential load transport in leaf-cutting ants, involving both direct and indirect (via dropping) load transfers, has repeatedly been reported in the literature [4, 5, 21, 24-28], although the possible adaptive value of such transportation schemes remains unclear [29].

The question arises why loaded leaf-cutting ants decide to transfer their fragments on their way to the nest, and what are the advantages of a sequential load transport. Fragments might be dropped or transferred if a minimum transport speed is not met by the carrier [28]. Although it seems conceivable that loads carried particularly slowly may eventually be abandoned by the carrier, a low travel speed does not necessarily indicate that a worker is not capable of carrying the load, or of walking faster [30, 31]. Travel speed may be reduced because of trail-marking activity by the carriers. Or workers may slow down because they try to pass the carried fragment to an unladen nestmate, and not because of the burden, thus being able to return to the source after unloading [5].

It is conceivable that sequential load transport in leafcutting ants may have been favoured because of a faster load delivery rate. These arguments are the core of the so-called "economic-transport hypothesis" [25]. It should be noted that "economic" in this context refers to the maximization of the transportation speed of a leaf fragment $[32,33]$, which at the colony level may result in an increased overall rate of resource delivery. In fact, maximization of leaf transportation has been proposed as the adaptive value of sequential transport in three leaf-cutting ant species that transfer loads or cache fragments on the ground $[4,5,28]$. In Atta colombica, direct transfer of leaf fragments between workers indeed resulted in a higher transportation speed after transfer, but it occurred in only $9 \%$ of the transported fragments. However, transferred fragments did not travel faster than those not transferred [28]. In another study on the same species, fragments recovered from a cache were also transported back to the nest more slowly than singlyforaged leaf fragments, leading the authors to argue that "leaf dropping, and, therefore, the switch to task partitioning is not in itself adaptive" [26]. In the grass-cutting ant Atta vollenweideri, transport time of single fragments carried sequentially was $25 \%$ longer, in average $8 \mathrm{~min}$ longer, than that of fragments carried to the nest by single workers along a $28 \mathrm{~m}$-trail [25]. Thus, in terms of foraging time and material transport rates, sequential load transport in Atta vollenweideri was less efficient than transport by single carriers.

Based on these results, an alternative hypothesis was advanced to account for the occurrence of sequential transport in grass-cutting ants [25]. It was argued that sequential transport was favoured during evolution as a way to enhance the information flow among foragers, thus leading to a quicker buildup of workers at particular harvesting places, and to an increased overall rate of resource transportation. These arguments are embodied into the "informationtransfer hypothesis" [34-36], which states that at newly discovered food sources, foraging ants compromise their individual transport rates of material in order to return early to the colony for information transfer. Foragers' performance as food carriers is, therefore, reduced, but the colony as a whole increases its harvesting rate due to the workers that gained information and participate in the collective gathering activity [29, 31]. Based on the informationtransfer hypothesis, the behavioural response of dropping or passing fragments in the grass-cutting ant, Atta vollenweideri, may have been selected for because of its positive effect on the information flow, rather than because of an improvement in the economics of load-carriage [25]. The importance of information transfer seems apparent when the colonywide foraging patterns of leaf-cutting ants are considered. Foraging trails can exceed $100 \mathrm{~m}$ in length $[18,37]$ and are characterised by strong branching into several side trails. Thus, outgoing workers have to choose between several bifurcations leading to different food patches. Sequential load transport could enhance information transfer in several aspects. By dropping a load at a trail bifurcation, successful workers may be able to return to the foraging site earlier following a freshly deposited pheromone trail and to chemically reinforce that trail sector much stronger than if they walk all the way to the nest, thus enhancing recruitment. Furthermore, fragments dropped on the trail, or being carried along it, may themselves act as information cues about what plant is currently harvested [38-40].

Up to now, both the information-transfer and the economic-transport hypotheses remain at the descriptive level, as no predictions of one of them have been experimentally addressed. For instance, if sequential load transport speeds up leaf transport, it should be expected to occur when the transporting ants move too slowly because of their burden, for example, when ants carry relatively large fragments. Based on the information-transfer hypothesis, sequential load transport is expected to occur more frequently under conditions in which information is worth transferring, for instance, upon the discovery of high-quality resources or when the colony is starved [31, 36, 41]. Grasscutting ants provide a particularly well-suited system for studies of sequential transport during foraging because ants harvest monocotyledonous plants near the ground [42], so that the whole process of cutting at the source until reaching the nest can be observed and experimentally manipulated.

The aim of the present study was to investigate the variables that trigger sequential load transport in the grasscutting ant Atta vollenweideri, and to test predictions of the two competing hypotheses presented above. Based on the arguments of the economic-transport hypothesis, fragment dropping (or transfer) by foragers occurs because of a mismatch between load size and body size at the individual level. Chains are, therefore, considered as a way to maximize the delivery rate of the collected loads. The probability of occurrence of sequential transport would, therefore, be expected to strongly depend on fragment size, and not necessarily on fragment quality, and should be higher for larger fragments that are difficult to carry. Alternatively, the information-transfer hypothesis states that the behavioral response of transferring fragments has been selected for because of its positive effect on the information flow 
during a foraging process. This hypothesis predicts that the formation of a transport chains should strongly depend on fragment quality rather than on fragment size. To distinguish between the different predictions, workers from an Atta vollenweideri field colony were presented with standardised paper fragments that differed either in size or in quality. The occurrence of transport chains was quantified by following marked grass fragments all their way to the nest and by recording when, where, and how fragments were transferred between carriers.

\section{Methods}

Field experiments were conducted at the biological field station of the "Reserva Ecológica El Bagual" in Formosa province, Chaco region of north Argentina, on a large mature colony of Atta vollenweideri. A single large colony was used because field colonies in the area varied greatly in size and worker-size distribution, making a standardization of size matching between load and worker sizes difficult to achieve. Ant foraging activity was strictly nocturnal, so that headlamps covered with a red filter were used for observations. Foragers showed no signs of disturbance because of the light.

The effects of load size on the occurrence of sequential transport were investigated on a natural trail of approximately $50 \mathrm{~m}$ length, at the end of which ants harvested a variety of grass species. Foraging ants were offered paper fragments of three different sizes, which were placed in the middle of the trail, at 26 and $33 \mathrm{~m}$ from the nest, over eight consecutive nights. Fragment sizes were chosen so as to separate the effects of load length and load mass on transport speed. Fragments differed either in length or in mass, but not in width, which was held constant at $3 \mathrm{~mm}$, as follows. "Short" fragments were $15 \mathrm{~mm}$ long and weighed in average $4.25 \mathrm{mg}$. "Long" fragments were $30 \mathrm{~mm}$ long with an average mass of $8.5 \mathrm{mg}$. Finally, "double" fragments were made by sticking two wet fragments together, forming a short double fragment of $15 \mathrm{~mm}$ in length, and an average mass of $8.5 \mathrm{mg}$. It is known that for fragments of similar mass, fragment length had a marked negative effect on manoeuvrability during transport and, as a consequence, on material transport rate $[43,44]$. Fragments were cut out of standard paper $\left(80 \mathrm{~g} / \mathrm{m}^{2}\right)$, soaked with orange juice for at least one hour, and then dried. In order to increase the acceptance of the paper fragments presented on the trail, we additionally placed an artificial "paper plant" $20 \mathrm{~cm}$ beside the main trail. It was created by soaking paper stripes of $15 \mathrm{~cm}$ length in orange juice, and by putting the stripes into a small plastic vial that was "planted" on the ground, as previously described [25]. Ants readily cut fragments from the paper plant and dropped them on the trail as observed for natural grass plants. During the measurements, however, only the offered, previously cut fragments were monitored. Such fragments were identified with pencilled marks and placed on the trail. After retrieval by workers, fragments were followed all their way to the nest. The occurrence of sequential transport, the transport time, the transport distance by each involved worker, as well as the "waiting times" of fragments, that is, the time a fragment was left on the trail before being retrieved by another worker, were recorded for each individual fragment. For those fragments transported sequentially, the total transport time included travel time, handling time by the foragers, and waiting times of the fragment. The workers involved in the sequential transport were collected after having passed their loads, and weighed (wet mass) at the nearest $0.1 \mathrm{mg}$.

The effect of food quality on the occurrence of sequential transport was investigated by presenting ants on a foraging trail, as described above, with paper fragments of constant size but different quality, as follows. Paper fragments were previously added either with pure orange juice (henceforth "orange fragments"), with a solution of $15 \%$ tannin in orange juice (henceforth "tannin-orange fragments"), or with a solution of $10 \%$ tannin in water (henceforth "tanninwater fragments"). Tannin is a natural plant secondary compound that has been shown to negatively influence leaf-cutting ant foraging and to inhibit the ant symbiotic fungus [45-47]. Fragments impregnated with these solutions are, therefore, expected to differ in quality and vary in their acceptance by the ants. Differences in acceptance were measured prior to the experiments by presenting simultaneously one fragment of each quality on the trail at $20 \mathrm{~m}$ from the nest, and by recording which one was taken first (see results). A trail that bifurcated into two branches at $31 \mathrm{~m}$ from the nest was used for the quality experiments. On the two arms, at $33 \mathrm{~m}$ from the nest, ants were presented with fragments of a given quality, that is, two different fragment qualities could be tested each experimental night. Initially, orange and tannin-orange fragments were offered over four consecutive nights, with the side of presentation alternating each night to control for potential side effects. In the following two nights, ants were presented in the same manner with orange fragments and tannin-water fragments, but due to methodological difficulties, only tannin-water fragments could be followed. All fragments were $20 \mathrm{~mm}$ long, $3 \mathrm{~mm}$ wide, and averaged $9 \mathrm{mg}$ in mass. Again, "paper plants" of the respective quality were presented $20 \mathrm{~cm}$ beside the trail, yet only the experimental, previously cut fragments were followed. A total of 41 orange, 42 tannin-orange, and 35 tannin-water fragments were followed all the way to the nest.

\section{Results}

3.1. Behaviour of the First Carriers. The occurrence of sequential transport strictly depends on the behaviour of the first worker that collected a fragment. Sequential transport occurred when this "first carrier" transferred its fragment directly to an outgoing nestmate that then turned back and run loaded to the nest, or when the first carrier dropped the fragment on the trail, and it was collected and further carried by another worker. Single first carriers were gently marked with a small dot of Edding 780 paint marker while collecting one orange paper fragment close to the "paper plant", on a side trail $1 \mathrm{~m}$ after a trail bifurcation, and its behaviour monitored ( $n=16$ carriers were observed). Observations lasted at least 45 to $60 \mathrm{~min}$, or until the carrier 
entered the nest. All first carriers were observed to continue foraging at the location where they had initially collected their first paper fragment, to deposit the fragment after a given distance, and to retrieve at least one further fragment. Most of them collected one or two additional fragments prior to entering the nest and were possibly at the end of their daily foraging period. Seven workers collected more than five further fragments and started to walk back once more to the patch during the observation time. Thus they were still within their foraging period when they were caught (Figure 1). Seven carriers returned to the nest during the observation time, and only one worker switched to another foraging site and continued foraging but collected small natural sticks.

Most first carriers did not cut any fragments, with the exception of two workers that cut one fragment each out of the paper plant after having collected several paper fragments. Regarding the load transfers, $36 \%$ of them occurred when the carrier reached the main trail. For those that continued to walk along the main trail, there was no preferred location for passing or dropping the fragments, that is, workers did not walk a fixed distance before fragment transfer. Even the distances covered by individuals that retrieved several fragments varied considerably. There was neither a relationship between ant body size and number of fragments retrieved (Spearman Rank Correlation Test: $y=2.9+0.05 x, r^{2}=0.02, R=0.2, n=16, P=.6$, NS) nor with the walking distance before fragment transfer $\left(y=2.4-0.008 x, r^{2}=0.002, R=0.06, n=68, P=.7, \mathrm{NS}\right)$.

3.2. General Description of Sequential Transport. Most transport chains consisted of two or three carriers, but occasionally up to five foragers were involved. When not directly transferred, fragments were dropped in the middle of the trail. Ants neither preferred certain places on the trail for dropping fragments, nor did they build up piles or caches at a given location. Dropped fragments attracted unladen foragers and were readily collected. Waiting time of fragments dropped by first carriers were significantly shorter than that of fragments deposited by us with forceps, suggesting that previously transported fragments had some chemical marks as a consequence of their handling by workers (waiting times of fragments deposited by first carriers, all fragment sizes pooled, mean $\pm \mathrm{SD}: 44 \pm 88 \mathrm{sec}, n=114$; untouched fragments: $139 \pm 166 \mathrm{sec}, n=141 ; U$-test: $U=2412, Z=$ 7.2, $P<.001)$.

With regard to the mode of fragment transfer, 29\% (range 14-54\%) of all fragments were transferred directly between the first and second carrier, that is, most of the transfers were indirect, via dropping. The ratio of direct transfers to the total number of transfers was independent of both fragment size and food quality (Chi-Square-Test: $P>.05$ for all pairs).

Based on direct observations, it was difficult to reveal what variables triggered a direct transfer between workers. In some cases, the first carrier was observed to reduce its walking speed and to move very slowly until a nestmate approached and took the fragment. In other cases, the carrier kept approaching unladen nestmates coming from

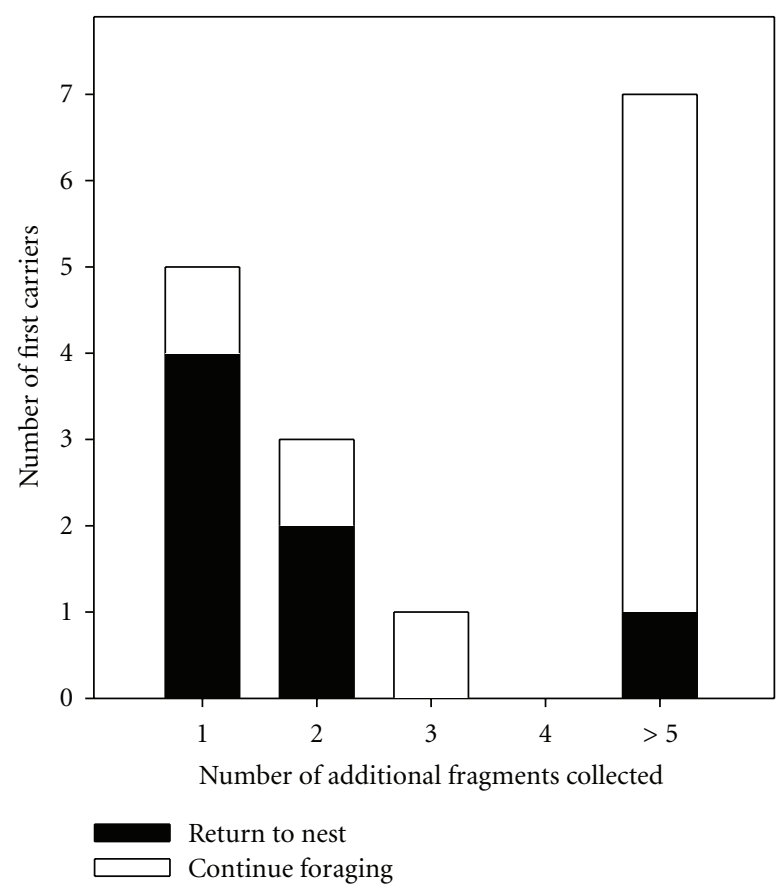

FIGURE 1: Number of additional fragments collected by the first carriers in a transport chain after the first fragment was dropped or directly transferred. Black bars indicate foragers that returned to the nest with a fragment during the observation time. White bars indicate foragers that continued to forage and returned to the patch at the end of the observation time.

the nest, whereby it rather meandered along the trail instead of walking straight ahead towards the nest. Additionally, unladen nestmates were observed to approach the first carrier, to antennate the fragment and then to take it. Several times, the two ants were observed to struggle for one or two minutes until one of them took the fragment.

3.3. Fragment Size and Sequential Transport. The probability of occurrence of sequential load carriage was independent of the size of the transported fragments (Figure 2). Fiftyfive percent of the short fragments $(n=47), 69 \%$ of the double $(n=52)$, and $57 \%$ of the long fragments $(n=46)$ were carried sequentially, these figures being not statistically different (Chi-Square-Test: $P>.2$ ).

As Atta workers are highly polymorph, the body size distribution of the different task groups (single, first, and last carrier within a transport chain) was compared, in order to elucidate whether the position along a transport chain was influenced by body size (Table 1). For all fragment types presented, the first carriers in a transport chain were smaller than the last carriers. First carriers were also smaller than single carriers, that is, those that transported the fragments all the way to the nest, for long and short fragments, but not for double ones. Body size of single and last carriers did not differ statistically. Furthermore, first carriers of long fragments were larger than first carriers of short fragments $\left(H_{1,52}=10.9, P<.005\right)$, and the same was true for last $\left(H_{1,50}=9.7, P<.005\right)$ and single carriers 


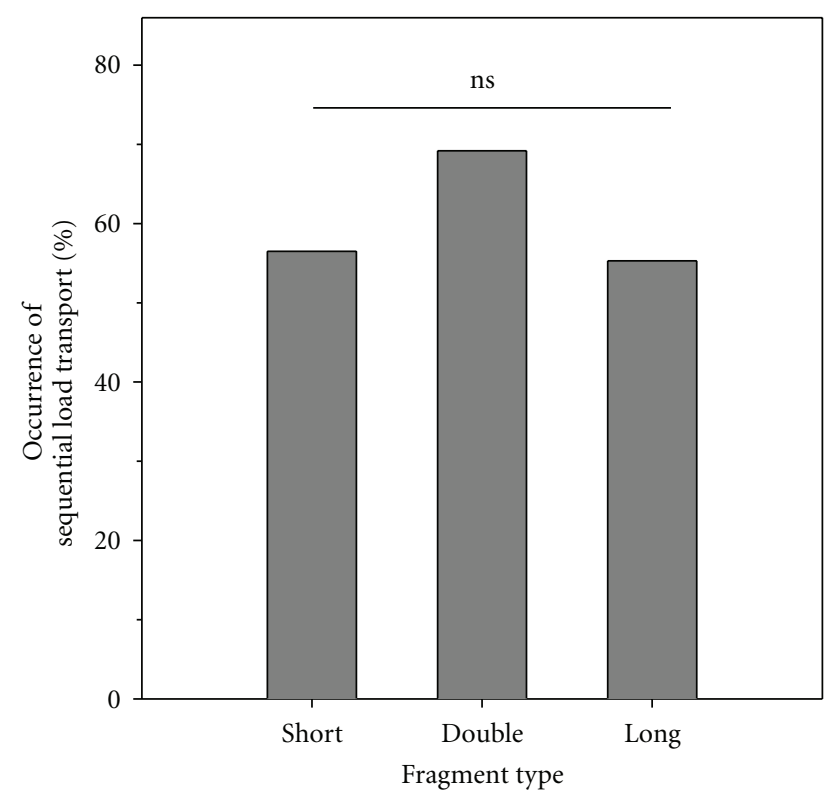

Figure 2: Occurrence of sequential load transport when ants were offered paper fragments of different size but similar quality (see text for Chi Square statistics).

$\left(H_{1,39}=6.4, P<.05\right)$. Thus, the size of the carriers in a transport chain depended on both their position within it and the size of the carried load.

The distance each fragment was carried by the first carrier until transfer did not depend on fragment size (Figure 3; mean \pm SD: short: $8.2 \pm 7.2 \mathrm{~m}$; double: $7.0 \pm 6.0 \mathrm{~m}$; long: $11.9 \pm 9.9 \mathrm{~m}$; Kruskal-Wallis-Test: $H_{2,88}=2.9, P=.2$, NS). Transfer distance was also independent of ant body size: for short and long fragments, a relationship, though not significant, between body mass of first carriers and walked distance was found, but the sign of the correlation differed between the two groups. No correlation was found for the double fragments (Spearman Rank Correlation Test: long: $y=1.0 x-0.6, R=0.39, t=2.09, n=26, P=.05$, NS; short: $y=-0.3 x+10.5, R=-0.41, t=-2.02, n=24$, $P=.06$, NS; double: $y=-0.2 x+9.9, R=-0.24, t=-1.41$, $n=34, P=.2, \mathrm{NS})$.

The transport time of fragments carried sequentially along $33 \mathrm{~m}$ was significantly longer than that of fragments carried by a single carrier all the way through, with differences ranging form 9 to $18 \mathrm{~min}$ (Figure 4 , mean \pm SD; short fragments: $30 \pm 18 \mathrm{~min}$ (single carrier), $44 \pm$ 23 min (transport chain), $U=103, Z=3.5, P<$ .001 ; double fragments: $32 \pm 9 \mathrm{~min}$ (single carrier), $41 \pm$ 14 min (transport chain), $U=174.5, Z=2.3, P<.05$; long fragments: $31 \pm 11 \mathrm{~min}$ (single carrier), $49 \pm 27 \mathrm{~min}$ (transport chain), $U$-test: $U=86.5, Z=4.0, P<.0001$ ).

3.4. Fragment Quality and Sequential Transport. The fragments of three different qualities initially presented as a choice on the trail were indeed ranked by the ants. Workers took first the orange fragments in $56 \%$ of the cases, the tannin-orange fragments in $28 \%$, and the tannin-water

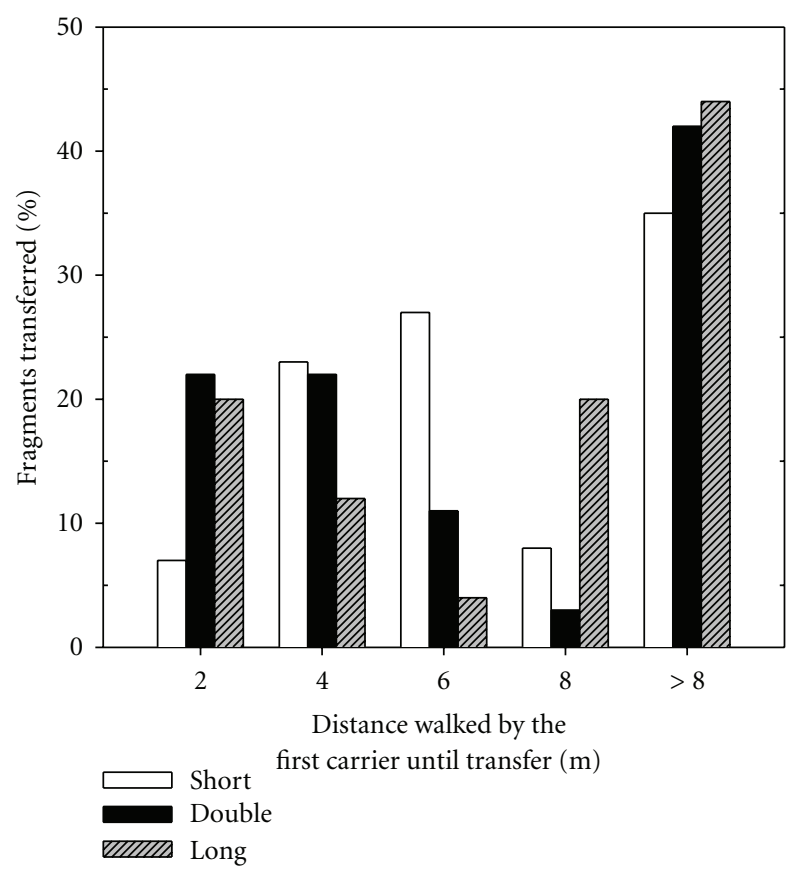

Figure 3: Distance at which first carriers in a transport chain transferred their fragments, for the three different fragment sizes assayed. Bars indicate how many loads were transferred within a distance category (bin width $2 \mathrm{~m}$ ). Fragments were offered and collected at " 0 meters," and $100 \%$ refers to all transferred fragments of a given size. Trail length was $33 \mathrm{~m}$. Transport distance for loads of different size did not differ significantly (statistics in text).

fragments in $16 \%$ of the cases (Chi-Square Test, $P<.05$ for all pairs, $n=39$ ). Thus, orange fragments were clearly the most preferred ones.

Sequential transport occurred significantly more often for the most preferred fragments (orange) than for the two others (Figure 5 ), that is, $81 \%$ of the orange fragments $(n=$ $41), 57 \%$ of the tannin-orange fragments $(n=42)$, and $40 \%$ of the tannin-water fragments $(n=35)$ were carried by transport chains (Chi-Square Test: orange versus tanninorange: $P<.05$; orange versus tannin-water: $P<.0005$; tannin-orange versus tannin-water: $P=.2$, NS). These values correspond to all fragments presented over the entire experimental period.

Fragment quality also affected the distance the first carrier walked before transferring the carried fragment. The highly attractive orange fragments were transferred after a significantly shorter distance than the less attractive tanninorange fragments (Figure 6; mean \pm SD; orange: $6.1 \pm 7.2 \mathrm{~m}$; tannin-orange: $\left.12.6 \pm 9.9 \mathrm{~m} ; H_{1,57}=7.6, P<.01\right)$. Thus, highly attractive fragments were transferred more often (Figure 5) and after shorter distances (Figure 6) than less attractive fragments. In addition, if only the direct transfers are considered, the place where they occurred significantly depended on the fragment quality. Orange fragments were directly transferred after distances much shorter than those at which tannin-orange fragments were directly transferred (mean \pm SD: orange: $6.9 \pm 5.5 \mathrm{~m}, n=8$; tannin-orange: 21.2 $\left.\pm 6.2 \mathrm{~m}, n=6 ; H_{1,14}=7.4, P<.01\right)$. As for the fragments 
TABLE 1: Body mass (mg) of carriers in a transport chain and single carriers that transported fragments of different sizes: short, double or long fragments. Data are means $\pm \mathrm{SD} ; N$ numbers in brackets. Comparisons after Kruskal-Wallis-ANOVA.

\begin{tabular}{|c|c|c|c|}
\hline & Short fragments & Double fragments & Long fragments \\
\hline First carrier & $8.7 \pm 4.5(26)$ & $11.4 \pm 6.1(35)$ & $12.7 \pm 4.2(25)$ \\
\hline Last carrier & $13.7 \pm 9.3(25)$ & $15.5 \pm 7.1(36)$ & $19.3 \pm 10.7(26)$ \\
\hline Single carrier & $12.1 \pm 4.0(18)$ & $14.0 \pm 7.6(16)$ & $16.7 \pm 5.1(21)$ \\
\hline \multirow[t]{2}{*}{ Kruskal-Wallis-ANOVA: } & $H_{(2,69)}=12.1$ & $H_{(2,87)}=7.7$ & $H_{(2,72)}=10.3$ \\
\hline & $P<.005$ & $P<.05$ & $P<.01$ \\
\hline \multicolumn{4}{|l|}{ Paired comparisons: } \\
\hline \multirow[t]{2}{*}{ First vs. Single } & $H_{(1,44)}=8.4$ & $H_{(1,51)}=1.4$ & $H_{(1,47)}=5.8$ \\
\hline & $P<.005$ & NS & $P<.05$ \\
\hline \multirow[t]{2}{*}{ First vs. Last } & $H_{(1,51)}=8.8$ & $H_{(1,71)}=7.2$ & $H_{(1,51)}=8.8$ \\
\hline & $P<.005$ & $P<.01$ & $P<.005$ \\
\hline \multirow[t]{2}{*}{ Single vs. Last } & $H_{(1,43)}=0.002$ & $H_{(1,52)}=1.8$ & $H_{(1,46)}=0.3$ \\
\hline & NS & NS & NS \\
\hline
\end{tabular}

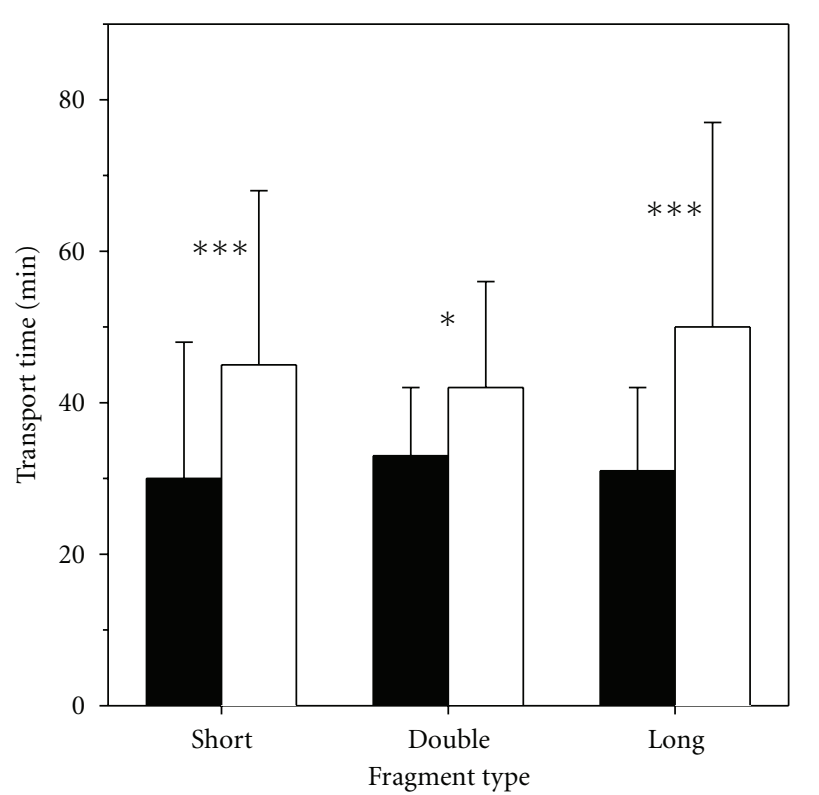

Single carrier

Transport chain

Figure 4: Transport time (mean \pm SD) of fragments transported by one carrier all the way to the nest (black bars) or by a transport chain (white bars). Transport time includes handling time of foragers and waiting times of a dropped fragment until transport was continued (statistics in text).

of different size, the distance walked by the first carriers until the transfer was independent of their body mass (Spearman Rank Correlation Test: orange: $R=-0.16, n=32, P=.4$, NS; tannin-orange: $R=-0.38, n=23, P=.07, \mathrm{NS})$.

\subsection{Load Transport in Other Contexts: Collection of Dry Plant} Fragments and Building Materials. Under natural conditions, not only freshly cut grass fragments are transported back to the nest along foraging trails, but also fallen, dry plant

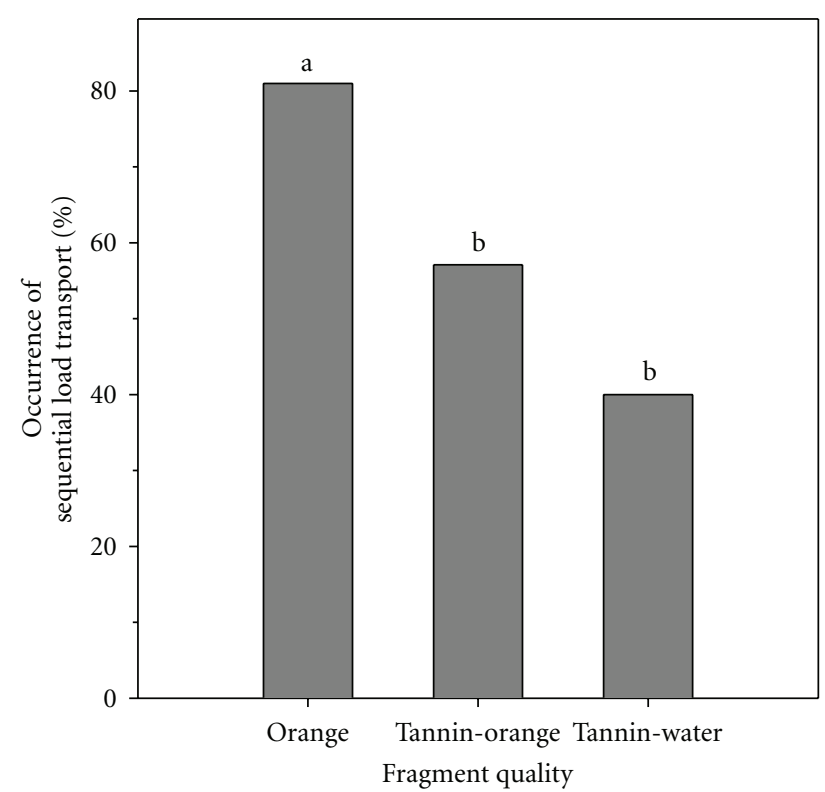

Figure 5: Occurrence of sequential load transport when ants were offered paper fragments of similar size but different quality. Bars sharing the same letter are not statistically different (see text for ChiSquare statistics).

fragments and twigs used as building materials to stabilize the nest structure. Such alternative scenarios allow the analysis of sequential transport in contexts other than the foraging one and may shed light on the benefits provided by a sequential load transport in more general terms. Detailed observations of fragment transport were performed at the study site both after a prolonged dry season, when colony foraging was reduced and workers mostly collected fallen plant fragments, and later after heavy rains, when workers moved along the trail and collected twigs, fallen fragments and even soil crumbs that were dropped around the nest entrances as building materials [48]. 


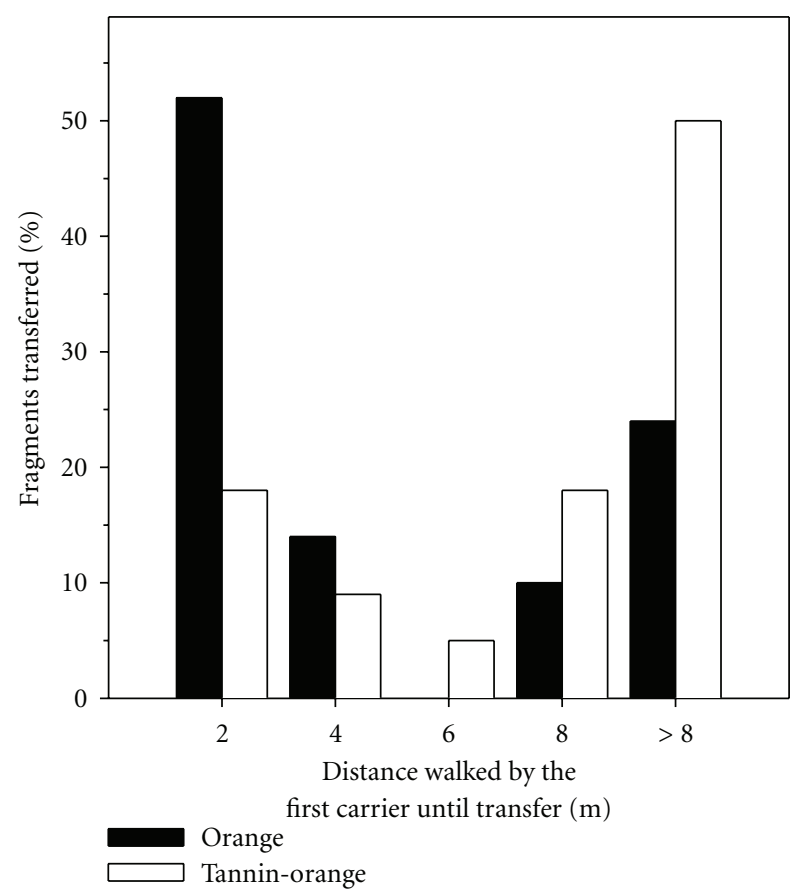

Figure 6: Distance at which first carriers in a transport chain transferred their fragments, for the different fragment qualities assayed. Bars indicate how many loads of a specific quality were transferred within a distance category (bin width $2 \mathrm{~m}$ ). Fragments were offered and collected at "0 meters," and $100 \%$ refers to all transferred fragments of a given quality. Trail length was $33 \mathrm{~m}$. High-quality fragments were dropped at a significantly shorter distance than low-quality fragments (statistics in text).

When collecting fallen, dry plant fragments, workers moved in small numbers on the trails (in average 7 loaded ants per minute), and laden ants were observed to carry their loads all the way to the nest, along a $15 \mathrm{~m}$ trail. No sequential transport of loads occurred $(n=45$ fragments were followed). Although no direct comparisons with highly active colonies could be made, a previous study reported that $36 \%$ of the fragments harvested from the sedge Cyperus (and 16\% of the collected paper fragments) at $10 \mathrm{~m}$ from the nest were transported sequentially [25]. After heavy rains, workers collecting wet plant fragments and twigs as building materials, $11 \mathrm{~m}$ away from the nest, transported them all the way to the nest without transfers ( $n=50$ loads observed). Workers moved in large numbers on the trail, comparable to a foraging context (in average 21 loaded ants per minute). They did not incorporate the building materials into the nest but dropped all them at the nest entrance.

\section{Discussion}

The present study tested predictions of two competing hypotheses concerning the adaptive value of sequential load transport in grass-cutting ants, Atta vollenweideri. In general terms, sequential transport via so-called "bucket brigades", in which all fragments and workers are always on the move, is expected to enhance the performance of individuals, so that workers are more likely to become specialists and thus more efficient $[12,17]$. True bucket brigades may in addition reduce queuing delays at both the source and destination, resulting in a higher group's overall rate of resource transportation $[8,13]$. In fact, an increased rate of load delivery has been proposed as the main benefit of sequential transport for several ant species $[4-6,28]$. However, in the ants Atta vollenweideri and Anoplolepis gracilipes, sequential transport took longer than transport by a single carrier all the way through (the present study and [25, 49]). In Atta, this resulted from delays associated with the careful lying down of the carried fragment, the waiting time until retrieval by another worker, and the subsequent handling time. Sequential load transport was therefore time consuming and resulted in a lower material transport rate than the nonsequential mode.

In the framework of the economic-transport hypothesis, fragments should be transferred whenever the carrier experienced a reduced transport speed, either because the fragment is too large for the carrying ant or the ant too small for the carried load. The present results, however, do not support this prediction, as neither an increase in fragment mass nor in fragment length affected the probability of occurrence of transport chains, even though they are known to markedly affect transport rates $[43,44]$. Because of stability constraints [44], larger loads should in addition be transferred after a shorter distance than lighter ones, yet this was not the case. Finally, if fragments should be transferred because of a mismatch between body and fragment size, fragments of a given size carried by small workers should be dropped at shorter distances than those carried by larger workers, yet there was no significant relationship between these variables. On the contrary, observations of the first carriers revealed that a high percentage of loads were transferred after the carrier reached the main trail, suggesting that the perception of a strong chemical trail, or the interactions with nestmates, triggered the load transfer [5, 50]. Taken together, the available data on the relationship between fragment size and occurrence of sequential transport do not provide support for the predictions of the economic-transport hypothesis.

Interestingly, first carriers were smaller than last carriers in a transport chain, as also reported for other ant species [48,49 ], and also smaller than single carriers that transported the fragment all the way to the nest. This appears $a$ priori to support the arguments of the economic-transport hypothesis, that is, fragments might be initially dropped because the first carriers were too small for the task to be efficiently performed. However, ants may drop the fragment not because they are too small for the task, but because they restrict their work on a short trail segment. Observations on the behaviour of foragers collecting dropped fragments make very unlikely that most of them (up to $100 \%$ of the orange fragments in our experiments) "erroneously" collected fragments they were unable to carry because of their size, thus needing to drop them after a short distance. Foragers seem to be very selective when collecting dropped fragments; workers were observed first to try to lift the load, before they either abandon the fragment and search for another one or take it up for carriage. And more important, why should small 
workers drop high-quality fragments more often than lowquality ones, if their decisions are based alone on fragment size and are the result of a mismatch between load and body sizes? The arguments of the economic-transport hypothesis fail to provide a compelling explanation.

Fragment quality was observed to markedly affect both the probability of occurrence of sequential transport and the distance walked by the first carrier before transfer. The first carriers transferred very attractive fragments more often, and after a shorter distance than less attractive ones. Intuitively, one would expect a worker carrying a high-quality fragment to be more motivated to carry it all the way back to the nest. So why should carriers transfer their fragments? Observations on the subsequent behaviour of the first carriers, as described in this study, may shed some light on this issue. All first carriers continued foraging, and all but one returned to the exact place where they collected the first fragment. Dropping or passing a load at the main trail after having carried it for a short distance has several consequences. First, fragment dropping after a given distance may allow workers to quickly go back to the harvested plant, making it easier for them to find the source again by following the freshly deposited pheromone trail. Moreover, an early return to the source may shorten the time needed to update information about the discovery, analogous to the reduction of dead time in a control system, thus allowing workers to switch to alternative resources whenever needed. Second, moving along a short-trail sector may enable workers to locally reinforce the pheromone marking better than after walking all the way to the nest, leading to a quicker establishment of a foraging column and a faster monopolisation of the discovered source, as demonstrated for foragers of the leafcutting ant, Atta sexdens [5]. It is important to note that field foraging trails can commonly exceed $50 \mathrm{~m}$ in length. In our experiments, ants usually needed 30 to $60 \mathrm{~min}$ to walk along the $33 \mathrm{~m}$ to reach the nest. This means that one single roundtrip would last one or two hours. In contrast, the observed first carriers managed up to 13 roundtrips per hour by foraging just on their short trail section.

Leaf- and grass-cutting ants forage along well-defined trunk trails leading to the harvested trees (in case of leaf cutters) or grass patches $[4,18,37,51]$. Trunk trails split up into several side branches, and foraging patches are not necessarily located directly beside a trail nor are they defined spots. This means that between patch and main trail, a distance without or with a poorly defined trail has usually to be covered, thus making the finding of a newly discovered source difficult. A. vollenweideri ants, like other leaf-cutting ants $[52,53]$, usually did not deplete sources, but switched to other plants within a few days (personal observations). The reasons for this behaviour remain unclear. Rapid induction of secondary deterring components in the harvested grasses may be involved [54], but no studies have been carried out to investigate this phenomenon. Hence, the dynamic pattern of trail use and the strong branching of the existing trails may have favoured the evolution of a system that allows quick information transfer.

In the context of information transfer, fragments dropped on the trail may in addition act as "signposts." It has been shown that leaf-cutting ant foragers learn the odors of the harvested resources $[39,40]$, and that the foragers' choices once at the patch depend on the material that is currently transported on the trail by their nestmates $[38,50]$. The odor of the carried fragments, or of those found on the trail, might function as stimulus for olfactory learning. In fact, as soon as a worker started to lay down its load, outgoing nestmates coming from the nest were strongly attracted to it. Most foragers, even those that continued on their way to the cutting site without a load, were observed to antennate the dropped fragments they encountered on the trail. Thus, outgoing foragers may obtain information about the harvested resources both by contacting laden nestmates along the trail and by finding dropped fragments on it. This information may stimulate them to search for the experienced plant species, thus leading them from the trail to the newly discovered plant. Such an active search for information about the loads being transported was described for Atta cephalotes as early as 1929 by Lutz [32], who observed "frequently, a returning laden forager is stopped momentarily by an outgoing nestmate which is apparently interested in what is being carried." The shorter waiting times of fragments that had been carried by workers, compared to those of "naive" fragments deposited by us on the trail, strongly suggests that dropped loads may have in addition been passively or actively marked by the ants.

We hitherto discussed scenarios that may have lead to the evolution of sequential transport in ants, yet, at the proximate level, the question about what triggers load transfer remains open. Our results provide no indication that load size or ant body size influenced the workers' decision to transfer their loads. The obtained correlations between body mass and covered distance were weak, sometimes of different sign, and showed in addition high variation. Moreover, individually marked ants dropped their loads in successive trips at very different distances. As mentioned above, a low transport speed because of a mismatch between load and body size was proposed to trigger fragment transfers in Atta colombica [28]. We did not record transport speed but measured the total time spent by each carrying ant, including handling times, interactions with nestmates, and so forth. Considering that the trail structure changes very much with distance, that is, trails are generally narrower, less cleared of vegetation, and with obstacles further away from the nest, average walking speed over the complete distance does not seem to represent a useful measure. More importantly, we often observed foragers walking very slowly or even stopping walking before dropping a load. These ants started at the source with a higher speed and then reduced their speed on the way, suggesting that they would have been able to continue walking at the same pace. The observed reduction in speed was often accompanied by a continuous approach to unladen nestmates, and a typical zig-zag walking pattern from one trail side to the other. Therefore, it could be argued that ants walked slowly because they were going to drop their loads, instead of that they dropped their loads because the burden forced them to walk at a slow pace. In addition, ants covering the section from the patch to the main trail were possibly involved in trail-marking, which 
may also have slowed them down. Further conditions that were shown to cause fragment dropping in leaf-cutting ants under laboratory conditions, such as "bottle necks" during transport $[20,21]$, were absent in our field study. There were in addition no specific dropping places that could have triggered dropping via positive feedback or the presence of pheromone marking [21], since the short waiting times of dropped fragments prevented the formation of piles. One possible trigger could be the interaction with unladen, outgoing workers, but this aspect needs further investigation.

Summing up, the present study demonstrated that neither an increase in fragment mass nor in fragment length alter the probability of occurrence of sequential transport. In addition, sequential load transport took longer than transport by a single carrier. However, the frequency of occurrence of sequential load transport increased with increasing fragment quality, independently of fragment size. High-quality fragments were not only transferred more frequently but also after much shorter distances than less attractive ones, which suggests that sequential transport is driven by the need to transfer information about the discovery. The lack of occurrence of sequential load transport in two other contexts that are not necessarily associated with high information demands, that is, the more opportunistic collection of fallen dry plant fragments or building materials, provides indirect support for the hypothesis that a sequential load transport in grass-cutting ants has been favoured during evolution because of an improvement in the information flow during foraging.

\section{Acknowledgments}

We dedicate this study to Professor Dr. Josué A. Núñez, University of Buenos Aires, Argentina, for his deep insights into social insect foraging behaviour and thank him for fruitful comments on an early draft. Thanks are also due to Bert Hölldobler for support and interest, to Christoph Kleineidam for encouraging discussions, and to an anonymous reviewer for several comments that improved the manuscript. Field work was performed at the wonderful Reserva Ecológica El Bagual (Alparamis SA-Aves Argentinas) in eastern Chaco, Province of Formosa, Argentina. We are very much indebted to the ornithologist Alejandro G. Di Giacomo, his field assistants, and especially Götz family for providing facilities at the Biological Station, daily help during our stays, and invaluable logistical support. Kerstin Fröhle, Kristin Strobel and Reza Kharrazian contributed valuable help during the field work. Financial funds were granted by the DAAD (PWA-Program with the Fundación Antorchas, Argentina) and the German Research Foundation (DFG-SFB 567).

\section{References}

[1] J. H. Sudd, “The transport of prey by ants," Behaviour , vol. 25, pp. 234-271, 1965.

[2] J. F. A. Traniello and S. N. Beshers, "Maximization of foraging efficiency and resource defense by group retrieval in the ant formica schaufussi," Behavioral Ecology \& Sociobiology, vol. 29, no. 4, pp. 283-289, 1991.

[3] T. J. Czaczkes and F. L. W. Ratnieks, "Simple rules result in the adaptive turning of food items to reduce drag during cooperative food transport in the ant Pheidole oxyops," Insectes Sociaux, vol. 58, pp. 91-96, 2011.

[4] H. G. Fowler and S. W. Robinson, "Foraging by Atta sexdens (Formicidae: Attini): seasonal patterns, caste and efficiency," Ecological Entomology, vol. 4, pp. 239-247, 1979.

[5] S. P. Hubbell, L. K. Johnson, E. Stanislav, B. Wilson, and H. Fowler, "Foraging by bucket-brigade in leaf-cutter ants," Biotropica, vol. 12, pp. 210-213, 1980.

[6] F. López, C. Agbogba, and I. Ndiaye, "Prey chain transfer behaviour in the African stink ant, Pachycondyla tarsata Fabr," Insectes Sociaux, vol. 47, no. 4, pp. 337-342, 2000.

[7] M. Pfeiffer and K. E. Linsenmair, "Polydomy and the organization of foraging in a colony of the Malaysian giant ant Camponotus gigas (Hym./Form.)," Oecologia, vol. 117, no. 4, pp. 579-590, 1998.

[8] J. L. Reyes and J. Fernández Haeger, "Sequential co-operative load transport in the seed-harvesting ant Messor barbarus," Insectes Sociaux, vol. 46, no. 2, pp. 119-125, 1999.

[9] R. L. Jeanne, "The evolution of the organization of work in social insects," Monitore Zoologico Italiano, vol. 20, pp. 119133, 1986.

[10] A. G. Hart and F. L. W. Ratnieks, "Why do honey-bee (Apis mellifera) foragers transfer nectar to several receivers? information improvement through multiple sampling in a biological system," Behavioral Ecology and Sociobiology, vol. 49, no. 4, pp. 244-250, 2001.

[11] T. D. Seeley, "Social foraging in honey bees: how nectar foragers assess their colony's nutritional status," Behavioral Ecology and Sociobiology, vol. 24, no. 3, pp. 181-199, 1989.

[12] J. J. Bartholdi III, D. D. Eisenstein, and R. D. Foley, "Performance of bucket brigades when work is stochastic," Operations Research, vol. 49, no. 5, pp. 710-719, 2001.

[13] R. L. Jeanne, "The organization of work in Polybia occidentalis: costs and benefits of specialization in a social wasp," Behavioral Ecology and Sociobiology, vol. 19, no. 5, pp. 333-341, 1986.

[14] A. G. Hart and F. L. W. Ratnieks, "Task partitioning, division of labour and nest compartmentalisation collectively isolate hazardous waste in the leafcutting ant Atta cephalotes," Behavioral Ecology and Sociobiology, vol. 49, no. 5, pp. 387392, 2001.

[15] C. Anderson and F. L. W. Ratnieks, "Task partitioning in insect societies. I. effect of colony size on queueing delay and colony ergonomic efficiency," American Naturalist, vol. 154, no. 5, pp. 521-535, 1999.

[16] F. L. W. Ratnieks and C. Anderson, "Task partitioning in insect societies," Insectes Sociaux, vol. 46, no. 2, pp. 95-108, 1999.

[17] C. Anderson, J. J. Boomsma, and J. J. Bartholdi III, "Task partitioning in insect societies: bucket brigades," Insectes Sociaux, vol. 49, no. 2, pp. 171-180, 2002.

[18] N. A. Weber, Gardening Ants-The Attines, vol. 92, The American Philosophical Society, Philadelphia, Pa, USA, 1972.

[19] E. O. Wilson, "Caste and division of labor in leaf-cutter ants (Hymenoptera: Formicidae: Atta). I. the overall pattern in A. sexdens," Behavioral Ecology and Sociobiology, vol. 7, no. 2, pp. 143-156, 1980.

[20] A. G. Hart, C. Anderson, and F. L. W. Ratnieks, "Task partitioning in leafcutting ants," Acta Ethologica, vol. 5, no. 1, pp. 1-11, 2002. 
[21] A. G. Hart and F. L. W. Ratnieks, "Leaf caching in Atta leafcutting ants: discrete cache formation through positive feedback," Animal Behaviour, vol. 59, no. 3, pp. 587-591, 2000.

[22] J. J. Howard, "Costs of trail construction and maintenance in the leaf-cutting ant Atta columbica," Behavioral Ecology and Sociobiology, vol. 49, no. 5, pp. 348-356, 2001.

[23] A. G. Hart and F. L. W. Ratnieks, "Waste management in the leaf-cutting ant Atta colombica," Behavioral Ecology, vol. 13, no. 2, pp. 224-231, 2002.

[24] J. Röschard and F. Roces, "Fragment-size determination and size-matching in the grass-cutting ant Atta vollenweideri depend on the distance from the nest," Journal of Tropical Ecology, vol. 19, no. 6, pp. 647-653, 2003.

[25] J. Röschard and F. Roces, "Cutters, carriers and transport chains: distance-dependent foraging strategies in the grasscutting ant Atta vollenweideri," Insectes Sociaux, vol. 50, no. 3, pp. 237-244, 2003.

[26] A. G. Hart and F. L. W. Ratnieks, "Leaf caching in the leafcutting ant Atta colombica: organizational shift, task partitioning and making the best of a bad job," Animal Behaviour, vol. 62, no. 2, pp. 227-234, 2001.

[27] J. F. Lopes, L. C. Forti, R. S. Camargo, A. O. Matos, and S. S. Verza, "The effect of trail length on task partitioning in three Acromyrmex species (Hymenoptera: Formicidae)," Sociobiology, vol. 42, no. 1, pp. 87-91, 2003.

[28] C. Anderson and J. L. V. Jadin, "The adaptive benefit of leaf transfer in Atta colombica," Insectes Sociaux, vol. 48, no. 4, pp. 404-405, 2001.

[29] F. Roces and M. Bollazzi, "Information transfer and the organization of foraging in grass- and leaf-cutting ants ," in Food Exploitation by Social Insects: Ecological, Behavioral, and Theoretical Approaches, S. Jarau and M. Hrncir, Eds., Contemporary Topics in Entomology Series, pp. 261-275, CRC Press, Boca Raton, FLa, USA, 2009.

[30] F. Roces, "Both evaluation of resource quality and speed of recruited leaf-cutting ants (Acromyrmex lundi) depend on their motivational state," Behavioral Ecology and Sociobiology, vol. 33, no. 3, pp. 183-189, 1993.

[31] M. Bollazzi and F. Roces, "Information needs at the beginning of foraging: grass-cutting ants trade off load size for a faster return to the nest," PLoS One, vol. 6, no. 3, article e17667, 2011.

[32] F. E. Lutz, "Observations on leaf-cutting ants," American Museum Novitates, vol. 388, pp. 1-21, 1929.

[33] S. G. Rudolph and C. Loudon, "Load size selection by foraging leaf-cutter ants (Atta cephalotes)," Ecological Entomology, vol. 11, no. 4, pp. 401-410, 1986.

[34] F. Roces and J. A. Núñez, "Information about food quality influences load-size selection in recruited leaf-cutting ants," Animal Behaviour, vol. 45, no. 1, pp. 135-143, 1993.

[35] J. A. Núñez, "Honeybee foraging strategies at a food source in relation to its distance from the hive and the rate of sugar flow," Journal of Apicultural Research, vol. 21, pp. 139-150, 1982.

[36] F. Roces, "Individual complexity and self-organization in foraging by leaf-cutting ants," Biological Bulletin, vol. 202, no. 3, pp. 306-313, 2002.

[37] T. Lewis, G. V. Pollard, and G. C. Dibley, "Rhythmic foraging in the leaf-cutting ant Atta cephalotes (L.) (Formicidae: Attini)," Journal of Animal Ecology, vol. 43, pp. 129-141, 1974.

[38] J. J. Howard, M. L. Henneman, G. A. Cronin, J. A. Fox, and G. Hormiga, "Conditioning of scouts and recruits during foraging by a leaf-cutting ant, Atta colombica," Animal Behaviour, vol. 52, no. 2, pp. 299-306, 1996.
[39] F. Roces, "Olfactory conditioning during the recruitment process in a leaf-cutting ant," Oecologia, vol. 83, no. 2, pp. 261262, 1990.

[40] F. Roces, "Odour learning and decision-making during food collection in the leaf-cutting ant Acromyrmex lundi," Insectes Sociaux, vol. 41, no. 3, pp. 235-239, 1994.

[41] F. Roces and B. Hölldobler, "Leaf density and a trade-off between load-size selection and recruitment behavior in the ant Atta cephalotes," Oecologia, vol. 97, no. 1, pp. 1-8, 1994.

[42] J. C. M. Jonkman, "Biology and ecology of the leaf cutting ant Atta vollenweideri Forel, 1893," Zeitschrift für angewandte Entomologie, vol. 81, pp. 140-148, 1976.

[43] J. Röschard and F. Roces, "The effect of load length, width and mass on transport rate in the grass-cutting ant Atta vollenweideri," Oecologia, vol. 131, no. 2, pp. 319-324, 2002.

[44] K. Moll, F. Roces, and W. Federle, "Foraging grass-cutting ants (Atta vollenweideri) maintain stability by balancing their loads with controlled head movements," Journal of Comparative Physiology, vol. 196, no. 7, pp. 471-480, 2010.

[45] C. M. Nichols-orians, "Condensed tannins, attine ants, and the performance of a symbiotic fungus," Journal of Chemical Ecology, vol. 17, no. 6, pp. 1177-1195, 1991.

[46] J. M. Cherrett, R. J. Powell, and D. J. Stradling, "The mutualism between leaf-cutting ants and their fungus," in Insect-Fungus Interactions, N. Wilding, N. M. Collins, P. M. Hammond, and J. F. Webber, Eds., pp. 93-120, Academic Press, London, UK, 1989.

[47] F. Roces and B. Hölldobler, "Use of stridulation in foraging leaf-cutting ants: mechanical support during cutting or shortrange recruitment signal?" Behavioral Ecology and Sociobiology, vol. 39, no. 5, pp. 293-299, 1996.

[48] M. Cosarinsky and F. Roces, "Neighbor leaf-cutting ants and mound-building termites: comparative nest micromorphology," Geoderma, vol. 141, no. 3-4, pp. 224-234, 2007.

[49] H. Y. Hsu, R. L. Yang, and S. B. Horng, "Sequential load transport in Anoplolepis gracilipes (Hymenoptera: Formicidae): a novel case of non-cooperation," Sociobiology, vol. 48, no. 2, pp. 571-584, 2006.

[50] A. G. Farji-Brener, S. Amador-Vargas, F. Chinchilla et al., "Information transfer in head-on encounters between leafcutting ant workers: food, trail condition or orientation cues?" Animal Behaviour, vol. 79, no. 2, pp. 343-349, 2010.

[51] C. Kost, E. G. De Oliveira, T. A. Knoch, and R. Wirth, "Spatiotemporal permanence and plasticity of foraging trails in young and mature leaf-cutting ant colonies (Atta spp.)," Journal of Tropical Ecology, vol. 21, no. 6, pp. 677-688, 2005.

[52] H. G. Fowler and E. W. Stiles, "Conservative resource management by leaf-cutting ants? the role of foraging territories and trails, and environmental patchiness," Sociobiology, vol. 5, pp. 25-41, 1980.

[53] J. J. Howard, "Infidelity of leafcutting ants to host plants: resource heterogeneity or defense induction?" Oecologia, vol. 82, no. 3, pp. 394-401, 1990.

[54] M. Vicari and D. R. Bazely, "Do grasses fight back? the case for antiherbivore defences," Trends in Ecology and Evolution, vol. 8, no. 4, pp. 137-141, 1993. 

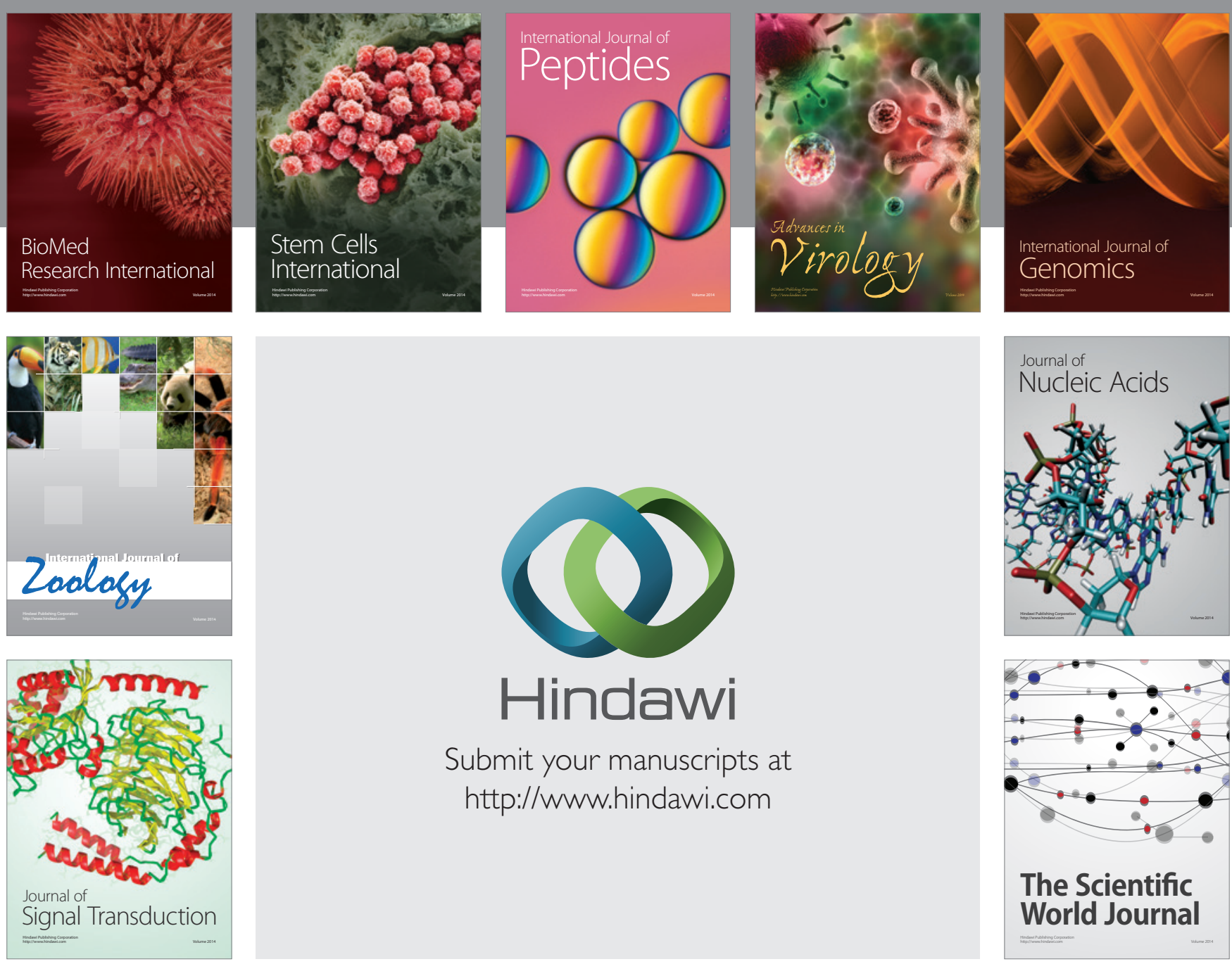

Submit your manuscripts at

http://www.hindawi.com
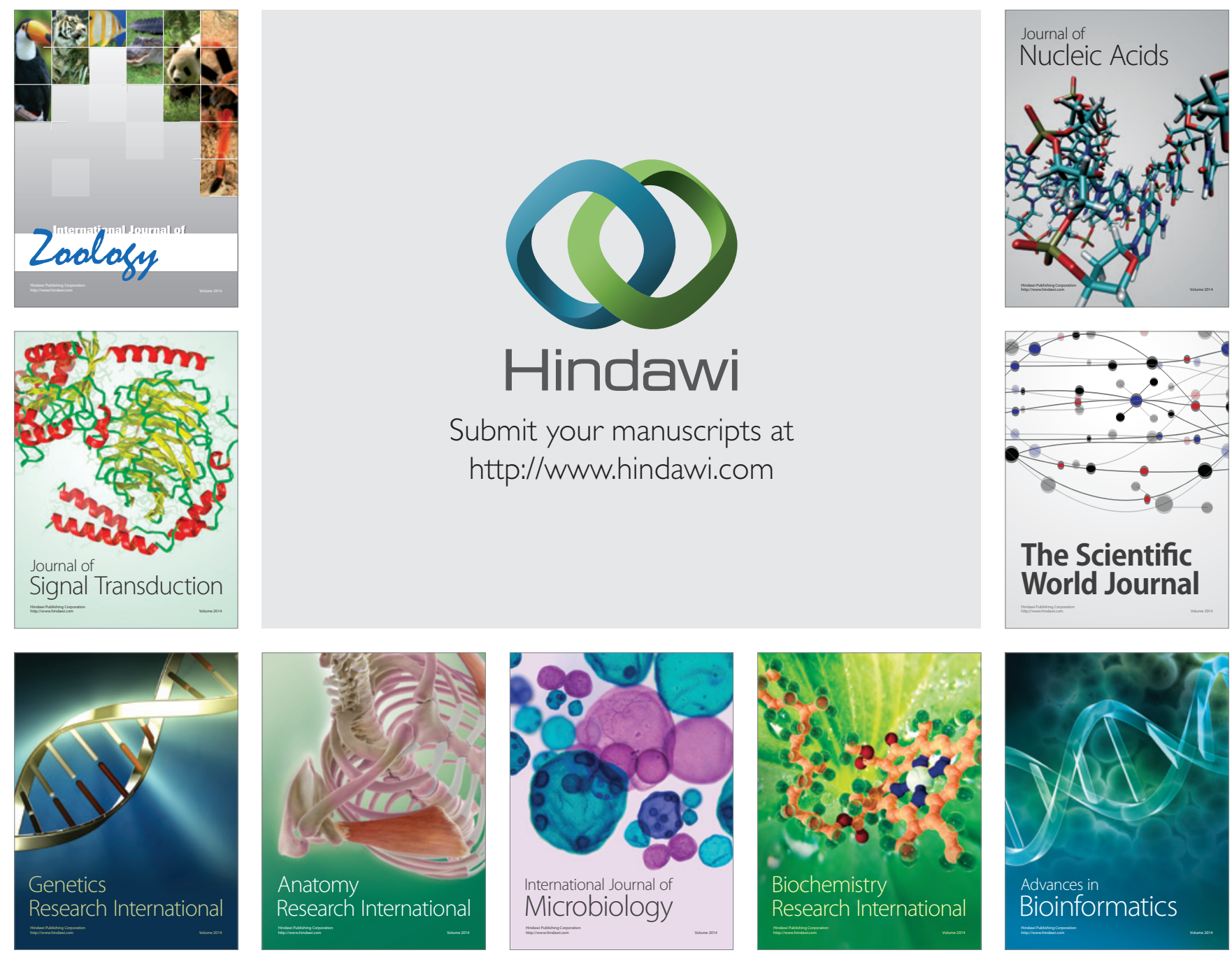

The Scientific World Journal
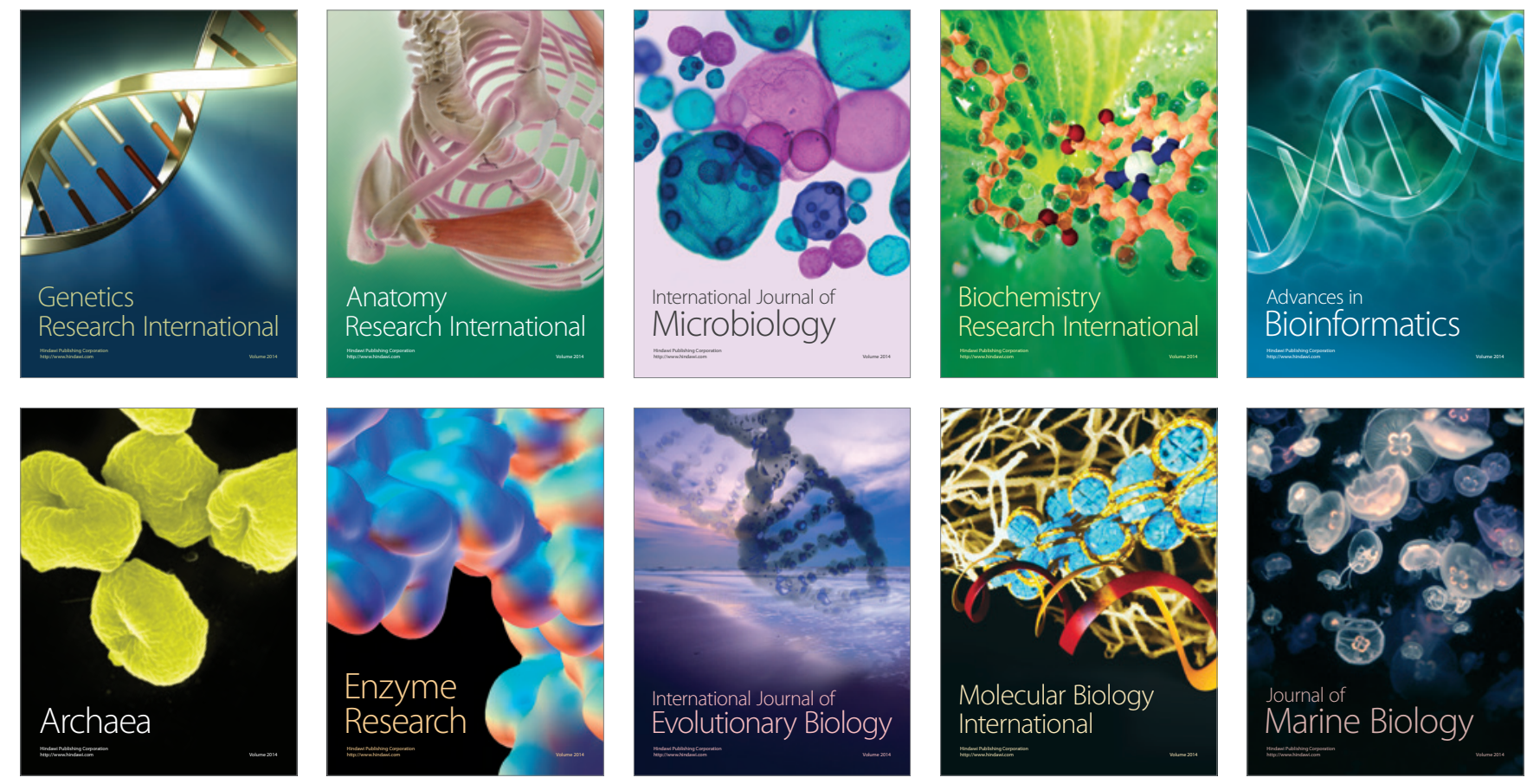